\title{
Placental Growth Factor in 24 to 30 Weeks of gestation as a predictor of Pre Eclampsia
}

\author{
Dr. Shanthi Sivakumar ${ }^{1}$, Dr.S.Nalina ${ }^{2}$, Dr.Nivedita.S ${ }^{3}$ \\ ${ }^{I}$ Dr.Shanthi Sivakumar, Associate Professor, Department of Obstetrics and Gynecology, Government \\ Thiruvannamalai Medical College and Hospital, Thiruvannamalai. \\ ${ }^{2}$ Dr. S.Nalina, Associate Professor, Department of Obstetrics and Gynaecology, Government Thiruvannamalai \\ Medical College and Hospital, Thiruvannamalai. \\ ${ }^{3}$ Dr.Nivedita.S, Postgraduate, Institute of Obstetrics and Gynaecology Madras Medical College. Chennai
}

\begin{abstract}
:
Background: Pre-eclampsia is one of the leading causes of maternal mortality and is lest understood in aspects of physiology; it awaits sensitive and specific tests for its prediction.

Objectives: 1.Placental growth factor is one test that is evolving as a predictor of preeclampsia. Present study aims to evaluate this aspect.

2. To evaluate the value of placental growth factor in predicting the severity of pre eclampsia.

3. To determine the association of placental growth factor with variables such as blood pressure and BMI.

Materials and methods: This prospective study was conducted among 80 pregnant mothers between 24 and 30 weeks of gestation to evaluate Placental Growth Factor in predicting the occurrence of preeclampsia. Fasting blood samples were collected from randomly selected pregnant mothers between 24 and 30 weeks and they were followed up for occurrence of preeclampsia and gestational age at which termination of pregnancy was done.

Results: Lower level of PlGF was found to be associated with pre eclampsia when compared to those who did not develop pre eclampsia.

Conclusion: PlGF as a predictor of pre eclampsia is more promising; the cut of level of PlGF in our population has to be established by more studies.
\end{abstract}

Key words: Placental Growth Factor, Predictor of Pre eclampsia.

\section{Introduction}

Preeclampsia is a multi-system pregnancy-specific disease which affects 2 to $8 \%$ of all pregnancies. It is characterized by placental and maternal vascular dysfunction. It is one of the leading cause of both maternal and fetal morbidity and as well as their mortality in the developing world. ${ }^{2}$ There is need to balance the risks between maternal and perinatal outcomes, as expectant management improves neonatal outcome, but at the same time worsens maternal conditions. ${ }^{3,45}$. Clinical diagnosis of preeclampsia in late stages gives very little scope for expectant management. ${ }^{6}$ Hence a pre-clinical diagnostic test which is able to predict pre eclampsia and its severity is needed. Evaluation of bio-markers and imaging techniques has shown that none have adequate sensitivity and specificity or the convenience for prediction or diagnosis of pre eclampsia but they help only in diagnosis of advanced disease with established end organ damages.

In the development of placenta, there is invasion of the cytotrophoblasts into the maternal spiral arterioles and the small caliber resistance vessels are transformed to high caliber conduit vessels. This is one of the early steps in placental development which starts from first trimester (10-12 weeks) and continues till 18 to 20 weeks of gestation. The two main components in the pathogenesis of pre eclampsia are the abnormal placentation and endothelial dysfunction. Abnormal placentation is often quoted as cause of pre eclampsia rather than the fetus. Symptoms of pre eclampsia persisted until the delivery of the placenta even in rare cases of extra uterine pregnancies. This brings to light the fact that the presence of fetus is not necessary for the development of pre eclampsia. ${ }^{7}$

The process of normal placental invasion by the cytotrophoblasts fails in pre eclampsia, leading to a shallow invasion of the spiral arterioles keeping them as small caliber resistance vessel leading to defective uteroplacental circulation and worsening placental perfusion. ${ }^{7,8}$ Placental growth factor (PIGF) belongs to the VEGF (vascular endothelial growth factor) sub-family and it has a key role in angiogenesis and vasculogenesis. It is abundantly seen in placental trophoblast and also in villous trophoblast, in addition to other tissues. In normal pregnancy the expression of PlGF protein and its mRNA are markedly increased during the second trimester. There is detachment of these syncytial knots from the syncytiotrophoblast, which form metabolically active multinucleated aggregates loaded with sFlt1 protein and mRNA which are accelerated in preeclampsia contributing to the maternal vascular injury. PIGF synthesized by syncytiotropoblast increases 
with gestataional age reaching peak by 26 to 30 weeks of gestation and declines towards term. ${ }^{9}$ PIGF is very much lowered in pre eclampsia and it has been proved that PIGF values are markedly lowered 5 weeks before the onset of pre eclampsia which assures us of its predictive capabilities. ${ }^{7}$

Levels of sFlt-1 are higher and PlGF lower in preeclamptic women, suggesting that it is mainly sourced from the placenta. ${ }^{10}$ PIGF to sFlt-1 ratio has been proposed to be one among the best methods for predicting preeclampsia before the onset of the disease. ${ }^{11,12,13}$ In pre eclamptic women, the PIGF levels were significantly lower not only in the plasma, but also in the urine. ${ }^{14}$

Plasma PIGF in early second trimester could be an effective predictor of early onset preeclampsia in women who are overweight/obese pregnant than in wom men with normal BMI or those who are over weight. ${ }^{15}$ Women who had pre eclampsia had significantly lower levels of PlGF where mean was $90 \mathrm{pg} / \mathrm{ml}$ in the pre eclamptic group as to $142 \mathrm{pg} / \mathrm{ml}$ in the control group. The maximum difference in the values of PlGF was noted in the weeks preceding pre eclampsia along with an increase in the sFlt-1 levels. The study conducted by Levine et al concluded that increased levels of sFlt-1 and reduced levels of PlGF is useful as a predictor for the subsequent development of preeclampsia. ${ }^{8}$

\section{Aim Of The Study}

The aims of study is to determine the diagnostic value of placental growth factor for predicting the occurrence of pre eclampsia in the gestational period from 24 to 30 weeks. To compare the value of placental growth factor in predicting mild or severe pre eclampsia. To determine the association of placental growth factor with variables such as blood pressure, BMI and fetal outcome.

\section{Materials And Methodology}

A prospective study was done in 80 randomly selected women who attended the casualty and antenatal OPD at the Institute of Obstetrics Gynecology, Chennai during the period from August 2014 to June 2015. The study protocol was approved by the Institutional ethical committee.

The inclusion criteria were:

(1) Pregnant mothers between 24 and 30 weeks of gestation

(2) Randomly selected population

(3) Antenatal mothers who were willing to deliver in our institution.

The exclusion criteria were:

(1) Diagnosed preeclampsia

(2) Chronic hypertension

(3) Multiple Gestation

(4) Patient not willing to participate in the study

Informed and written consent for the study was obtained from all patients. History was taken in detail and patients were subjected to clinical examination. Venous blood samples of $2.5 \mathrm{ml}$ with EDTA were collected from randomly selected pregnant mothers between 24 and 30 weeks to determine PlGF values by fluorescent immunoassay method. PIGF values are expressed in $\mathrm{pg} / \mathrm{ml}$. The collected data were analyzed using appropriate statistical methods. All antenatal mothers who were included in the study were followed up through admission, delivery and the immediate post-partum period.

Figure-I

The age distributions of the patients are represented in the below chart.

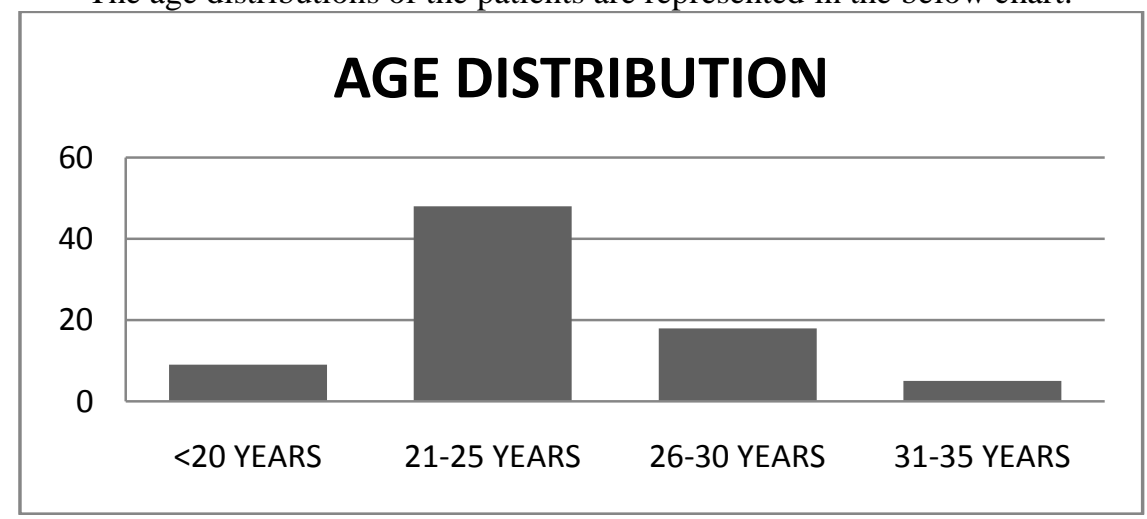


Figure-II

Mean BMI And Occurrence Of Pre Eclampsia

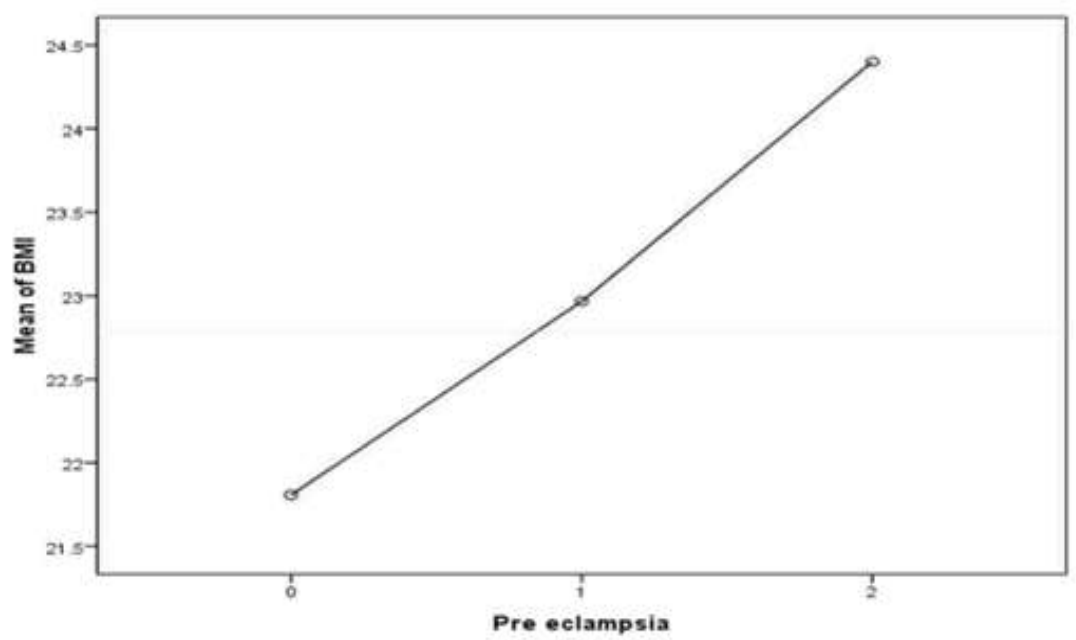

The mean BMI was 22.97 with a standard deviation of 2.004 among those who developed mild pre eclampsia and 24.40 with a standard deviation of 4.391 among those who developed severe pre eclampsia.

FIGURE-III

Scatter diagram showing correlation between Diastolic BP and PIGF values with a significance level of $\mathbf{P}=\mathbf{0 . 0 0 3 2}$

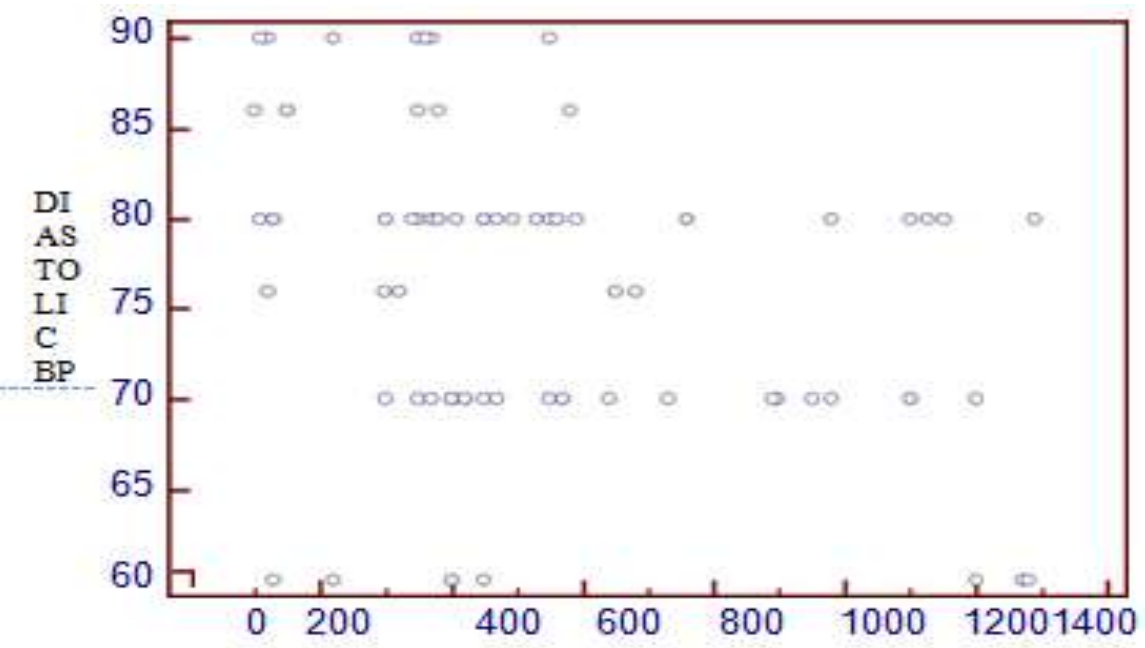

TABLE-I

\begin{tabular}{|l|l|}
\multicolumn{2}{|c|}{ Correlation } \\
\hline Sample size & 80 \\
\hline Correlation coefficient $\mathrm{r}$ & -0.3258 \\
\hline Significance level & $\mathrm{P}=0.0032$ \\
\hline 95\% Confidence interval for $\mathrm{r}$ & -0.5091 to -0.1143 \\
\hline
\end{tabular}

\begin{tabular}{|l|l|l|l|}
\hline & Variable Y & & Diastolic_BP \\
\cline { 3 - 3 } & & Diastolic BP \\
\hline & & & \\
\hline & & & \\
\hline & Variable X & & PLGF_Values \\
\cline { 3 - 3 } & & & PLGF Values \\
\hline & & & \\
\hline
\end{tabular}




\section{FIGURE-IV}

Scatter diagram showing correlation between Systolic BP and

$\mathrm{PlGF}$ values with a significance level of $\mathrm{P}=0.0013$

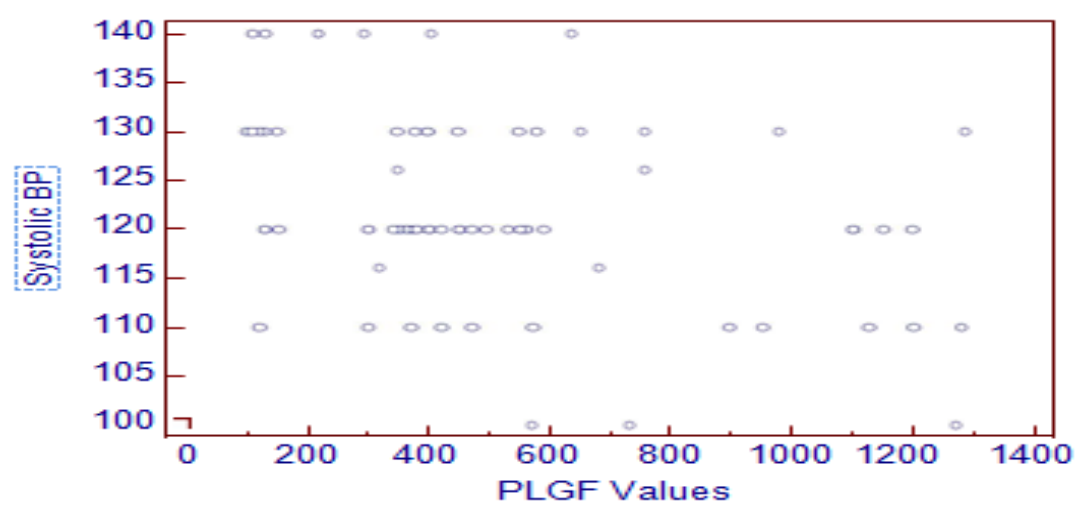

TABLE-II Correlation

\begin{tabular}{|l|l|l|l|}
\hline & Variable Y & & Systolic_BP \\
\cline { 3 - 3 } & & Systolic BP \\
\hline & & & \\
\hline & & & \\
\hline & Variable X & & PLGF_Values \\
\cline { 3 - 3 } & & & PLGF Values \\
\hline & & & \\
\hline & & \\
\hline
\end{tabular}

\begin{tabular}{|l|l|l|}
\hline Sample size & & 80 \\
\hline Correlation coefficient $\mathrm{r}$ & & \\
\hline & & -0.3541 \\
\hline Significance level & & \\
\hline & & $\mathrm{P}=0.0013$ \\
\hline $95 \%$ Confidence interval for $\mathrm{r}$ & & \\
\hline & & -0.5324 to -0.1457 \\
\hline
\end{tabular}

Area under the ROC curve (AUC)

\begin{tabular}{|c|c|c|}
\hline \multicolumn{2}{|c|}{ Area under the ROC curve (AUC) } & 0.915254 \\
\hline Standard Error $^{\mathrm{a}}$ & & 0.0370 \\
\hline $95 \%$ Confidence interval $^{\mathrm{b}}$ & & 0.831461 to 0.965866 \\
\hline z statistic & & 11.234 \\
\hline Significance level P (Area= & & $<0.0001$ \\
\hline${ }^{\mathrm{a}}$ DeLong et al., 1988 & & \\
\hline${ }^{\mathrm{b}}$ Binomial exact & & \\
\hline Youden index & & \\
\hline Youden index $\mathrm{J}$ & 0.7078 & \\
\hline Associated criterion & $\leq 350$ & \\
\hline
\end{tabular}

21 patients out of 80 samples had developed pre eclampsia (26.5\%).6 out of the 21 patients developed severe pre eclampsia.14 out of 80 patients had previous history of pre eclampsia.22 out of 80 patients had proteinuria. All 21 patients who developed pre eclampsia had proteinuria.1 patient had isolated proteinuria without pre eclampsia 
TABLE- III Criterion values and coordinates of the ROC curve

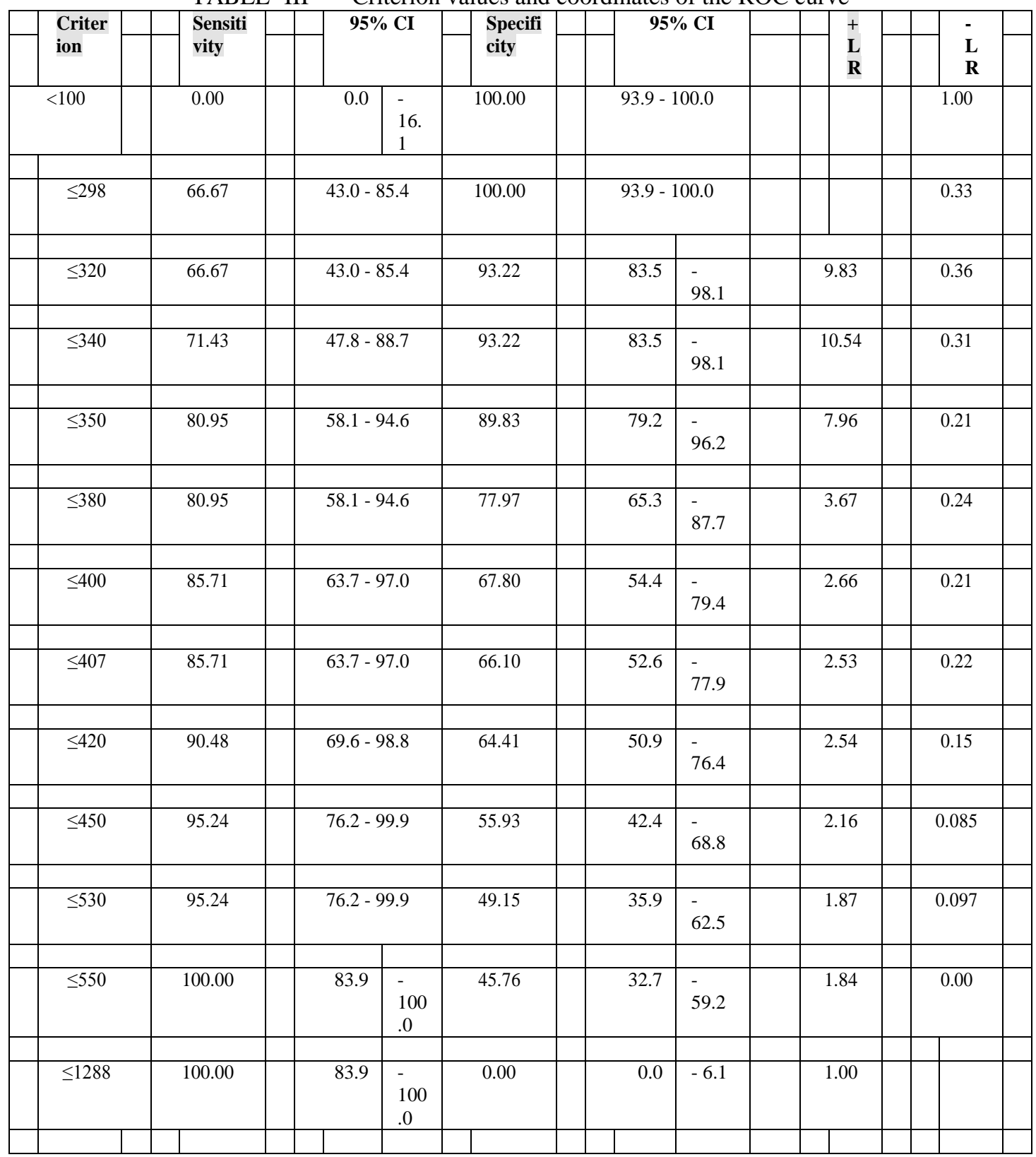

The sensitivity and specificity are $80.95 \%$ and $89.83 \%$ respectively, for PlGF criteria of $\leq 350$.

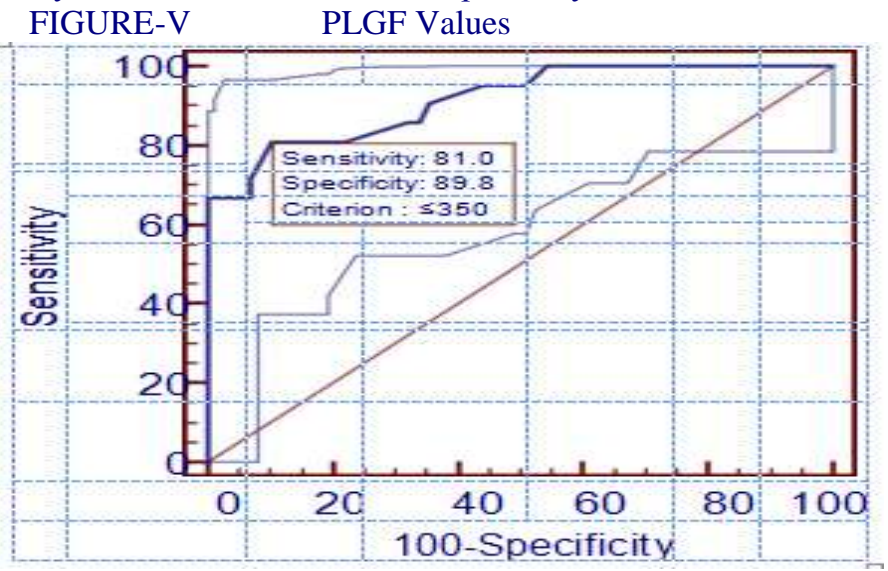


Of the 80 study patients, $14(17.5 \%)$ had previous history of pre eclampsia and $10(71.4 \%)$ among those with previous history of pre eclampsia, developed subsequent pre eclampsia.

So there is a statistically significant association between previous history of pre eclampsia and subsequent preeclampsia in our study.

Distribution of gestational age at which pregnancy was terminated in Normotensive mothers compared with preeclamptic mothers is shown in bar diagram below

\section{FIGURE-VI}

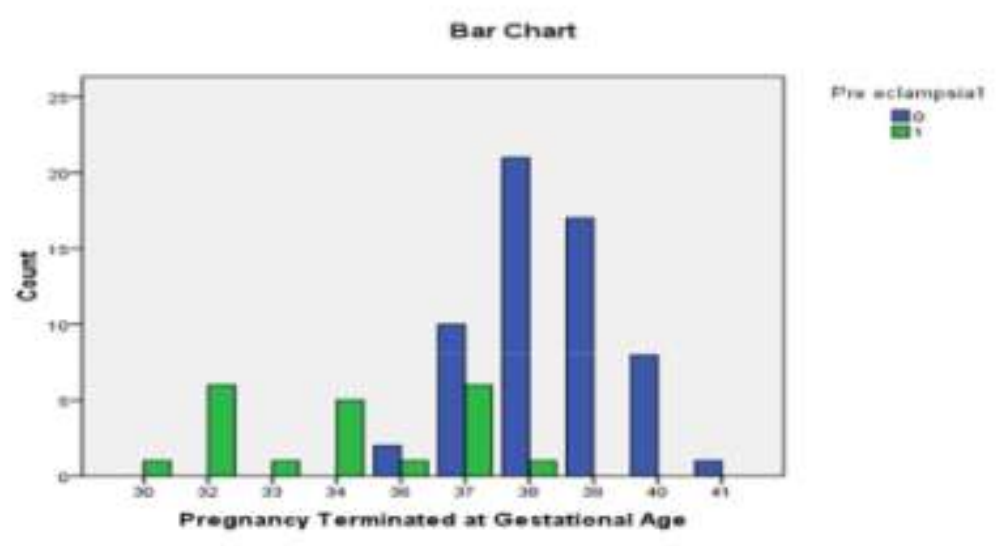

The blue bars represent those without pre eclampsia and the green bar represents the pre eclamptic patients.

Pre eclamptic patients had pregnancies terminated at earlier gestational age compared to those who were normal and carried it to term. The patients who developed severe pre eclampsia terminated by 32 weeeks $(\mathrm{n}=6 ; 28.6 \%)$ where as the those who had mild pre eclampsiacarried their pregnancy till 37 weeks, $(\mathrm{n}=6 ; 28.6 \%)$.

TAB LE-IV Anova

Pregnancy Terminated at Gestational Age

\begin{tabular}{|c|c|c|c|c|c|}
\hline & Sum of & \multirow[t]{2}{*}{ Df } & \multirow[t]{2}{*}{ Mean Square } & \multirow[t]{2}{*}{$\mathbf{F}$} & \multirow[t]{2}{*}{ Sig. } \\
\hline & Squares & & & & \\
\hline Between Groups & 286.324 & 2 & 143.162 & 75.059 & .000 \\
\hline Within Groups & 146.863 & 77 & 1.907 & & \\
\hline Total & 433.187 & 79 & & & \\
\hline & & & & & \\
\hline
\end{tabular}

More severe the degree of pre eclampsia the earlier the pregnancy was terminated.

\section{distribution of gestational age at which pregnancy was terminated} FIGURE-VII

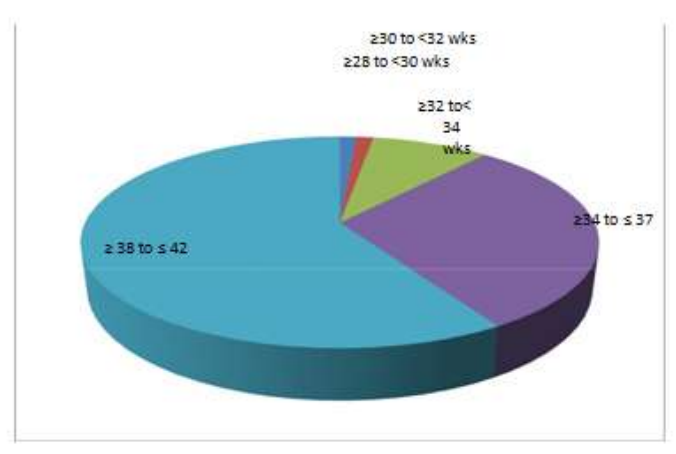

Of the 80 patients, 47 delivered at term $(58.75 \%), 33$ delivered preterm $(41.25 \%) .3$ patients had pregnancy terminated within 2 weeks of detecting low PIGF value. Out of the 3 patients, 2 had severe pre eclampsia, all 3 patients were $2^{\text {nd }}$ gravida, all 3 underwent cesarean sections. 2 out of the 3 babies showed features of IUGR.2 out of the 3 patients had previous history of pre eclampsia. In this study, Youden index is 
0.7078 and Area under the ROC curve is 0.92 which implies the diagnostic accuracy of PlGF is significant with a sensitivity and specificity of $80.95 \%$ and $89.83 \%$ respectively, for PlGF criteria of $\leq 350$.

\section{Discussion}

Serum PIGF in early second trimester could be an effective predictor of early onset preeclampsia in women who are overweight/obese pregnant than in women with normal BMI or who are underweight ${ }^{15}$, our study correlates with this study by Ghosh et al.

In his study Akolekar concluded that a combination of maternal characteristics including the obstetric history, uterine artery PI and maternal serum PlGF taken between 11 and 13 weeks would prove to be an effective screening tool for patients suspected to develop pre eclampsia later on in their pregnancy. ${ }^{16}$

Pre eclampsia had an increased incidence of 3.2 times that of the control group with confidence interval of $95 \%$, and the mean PIGF value was $62.5 \mathrm{pg} / \mathrm{ml}$ in pre eclamptic individuals. This study by Necmiye Dover concluded that low PIGF values in the second trimester have increased risk of developing pre eclampsia. ${ }^{17}$

Our study correlates well with this finding

Chikako Hirashima,in his study concluded that the values of PIGF or the sFlt-1/PIGF ratio appears to be clinically useful in the second trimester and also useful in the prediction of early onset pre eclampsia .In the early third trimester the combination of angiogenesis-related factors and other risk factors yielded the best LR+. ${ }^{18}$ Further studies are needed to confirm the findings and in combination may be a better predictor of pre eclampsia. Bolin et al has reviewed articles and has stated that in the first trimester, maternal characteristics such as mean arterial pressure, uterine artery pulsatility index and the biochemical markers PAPP-A and PIGF is of predictive value with 95\% specificity and 93\% sensitivity for early-onset and $36 \%$ for late-onset preeclampsia. ${ }^{19}$

The threshold value of PIGF at which a women would develop pre eclampsia, has not been clearly defined among the Indian population which once again states the need for more work on this accurate predictive test in order to individualize the level of surveillance during pregnancy.

\section{Conclusion}

Placental Growth Factor (PIGF) levels were significantly lower in patients prone to develop pre eclampsia. It also helps in risk stratification of pre eclamptic patients, as mild and severe pre eclampsia thereby early detection and appropriate management is possible in these patients. Studies with larger population size are needed in our setting to further define the diagnostic accuracy and predictive capabilities of the various angiogenic markers.

\section{Bibilography}

[1]. World Health Organization. Make Every Mother and Child Count. World Health Report, 2005. World Health Organization: Geneva, Switzerland, 2005.

[2]. Lewis G (ed). Confidential Enquiries into Maternal and Child Health. Why Mothers Die 2000-2002: The Sixth Report of United Kingdom Confidential Enquiries Into Maternal Deaths in the United Kingdom.RCOG Press: London, 2004.

[3]. Dekker G, Sibai B (2001) Primary, secondary, and tertiary prevention of pre-eclampsia. Lancet 357: 209-215. doi: 10.1016/S01406736(00) 03599

[4]. Belghiti J, Kayem G, Tsatsaris V, Goffinet F, Sibai BM, et al. (2011) Benefits and risks of expectant management of severe preeclampsia at less than 26 weeks gestation: the impact of gestational age and severe fetal growth restriction. Am J ObstetGynecol 205: 465 e461-466. doi: 10.1016/j.ajog.2011.06.062

[5]. Odendaal HJ, Pattinson RC, Bam R, Grove D, Kotze TJ (1990) Aggressive or expectant management for patients with severe preeclampsia between 28-34 weeks' gestation: a randomized controlled trial. ObstetGynecol 76: 1070-1075.

[6]. Jeanne Sibiude mail, Jean Guibourdenche, Marie-Danielle Dionne, Camille Le Ray, Placental Growth Factor for the Prediction of Adverse Outcomes in Patients with Suspected Preeclampsia or Intrauterine Growth Restriction; Published: November 28, 2012DOI: 10.1371/journal.pone.0050208

[7]. Lakshmi Tanuja Petla, Rosy Chikkala :Biomarkers for the management of pre-eclampsia in pregnant women, Indian J Med Res 138, July 2013, pp 60-67

[8]. Levine RJ, Maynard SE, Qian C, Lim KH, England LJ, Yu KF, Schisterman EF, Thadhani R, Sachs BP, Epstein FH, Sibai BM, Sukhatme VP, Karumanchi SA. Circulating angiogenic factors and the risk of preeclampsia. N Engl J Med.2004; 350: 672-683.

[9]. Knudsen UB, Kronborg CS, Von Dadelszen, Kopfer K, Lee SW, Vittinghus E, Allen JG, Redman CW. A single rapid point-of-care placental growth factor determination as an aid in the diagnosis of preeclampsia. Pregnancy Hypertens. 2011;2:8-15.Google Scholar

[10]. Chesley LC. History and epidemiology of preeclampsia-eclampsia. ClinObstet Gynecol. 1984;27(4):801-20.

[11]. Hertig A, Liere P23. . New markers in preeclampsia. ClinChimActa 2010; $411: 1591-5$.

[12]. Romero R, Nien JK, Espinoza J, Todem D, Fu W, Chung H, 24. et al. A longitudinal study of angiogenic (placental growth factor) and anti-angiogenic (soluble endoglin and soluble vascular endothelial growth factor receptor-1) factors in normal pregnancy and patients destined to develop preeclampsia and deliver a small-for-gestational-age neonate. J Maternal Fetal Neonatal Med 2008; 21 : 9-23.

[13]. Lapaire O, Shennan A, Stepan H. The preeclampsia biomarkers soluble fms-like tyrosine kinase-1 and placental growth factor: current knowledge, clinical implications and future application. Eur J ObstetGynecolReprodBiol 2010; 151 : 122-9

[14]. Betsy Varughese, Rajesh Kumar, NeerjaBhatla, S.N Dwivedi, ManojDhingra, RenuDhingra. Urinary Placental Growth Factor: A Promising Marker for Screening Preeclampsia;International Journal of Scientific and Research Publications, Volume 2, Issue 11, November 2012 
[15]. Ghosh SK, Raheja S, Tuli A, Raghunandan C, Agarwal S. Serum placental growthfactor as a predictor of early onset preeclampsia in overweight/obese pregnantwomen. J Am SocHypertens. 2013 Mar-Apr;7(2):137-48 doi:10.1016/j.jash.2012.12.006. Epub 2013 Feb 6. PubMed PMID: 23394804.d

[16]. Akolekar R, Syngelaki A, Sarquis R, Zvanca M, Nicolaides KH. Prediction of early, intermediate and late pre-eclampsia from maternal factors, biophysical and biochemical markers at 11-13 weeks. Prenatal Diagn 2011;31(1):66-74.

[17]. Necmiye Dover, $囚$ Hacer C. Gulerman, SevkiCelen, SerkanKahyaoglu, and OkanYenicesuPlacental Growth Factor: As an Early Second Trimester Predictive Marker for Preeclampsia in Normal and High-Risk Pregnancies in a Turkish PopulationJObstetGynaecol India. 2013 Jun; 63(3): 158-163.

[18]. Hirashima C, Ohkuchi A, Takahashi K, Usui R, Matsubara S, et al. (2014) Prediction of Early-Onset Preeclampsia Using Angiogenesis-Related Factors. Med J ObstetGynecol 2(2): 1025.

[19]. Bolin, M. 2012. Pre-eclampsia - Possible to Predict?: A Biochemical and Epidemiological Study of Pre-eclampsia. ActaUniversitatisUpsaliensis. Digital Comprehensive Summaries of Uppsala Dissertations from the Faculty of Medicine 835. 66 pp. Uppsala. ISBN 978-91-554-8523-8 